\title{
A ORDEM DO CONCRETO N'AS MIL E UMA NOITES
}

Marcelo Peloggio*

RESUMO: Partindo do caráter relativo da noção de "realidade concreta", o presente ensaio busca mostrar que, sob as imagens fantásticas dos contos d'As mil e uma noites, revela-se uma descrição notadamente objetiva das relações humanas, o que lhe torna o sistema de idéias universal.

PALAVRAS-CHAVE: Teoria da arte, Real/irreal, Literatura.

ABSTRACT: Based on the relative concern in relation to the idea of a "concrete reality", the recent study aims at illustrating that, relying on the focus on the fantastic images of The thousand-and-one nights' short stories, a notably objective description of the human relationships is revealed. This revelation makes the system of ideas in these short stories universal.

KEY WORDS: Theory of art, Real/unreal, Literature.

*Universidade Federal Fluminense

Diz-se freqüentemente que a arte tem por empresa a "execução 
prática de uma idéia". Nada mais perigoso, se for o caso de se considerar o fenômeno artístico tomado em si mesmo. Diante do objeto estético, em toda a sua extensão e espessura, é costume, em geral, o elogio à capacidade técnica e criativa do artista. E, sob tal ângulo, sua sensibilidade e liberdade mais parecem traduzir um não sei quê de meta - ainda que por meio delas as notas mais expressivas da alma recebam luz própria. É como se o artista buscasse em algum sítio, longe da vida, os dados com os quais elabora sua representação do mundo, o qual aparentemente lhe diz respeito. Ora, assim falando, dirigimo-nos mais precisamente ao idealismo.

Mas é preciso considerar, independente dessa fonte misteriosa, na qual seu mundo interior por uma razão qualquer se radica, que o artista não haverá de exprimir senão preceitos e valores que são nossos, ou melhor: que nos seriam a princípio inteligíveis, ainda que por força das circunstâncias sociais e históricas nos pareçam inauditos, impossíveis de se classificar.

O que queremos mostrar é justamente o contrário. Ao plano geral de uma obra não corresponderia nenhum princípio ou ensinamento estranhos a seu público, e que, por isso mesmo, a leva em conta como informação estética. Se nos parecem estranhos ou difíceis de se imaginar como algo inscrito no mundo empírico, é porque é do ser mesmo da arte oferecer, em maior ou menor grau, "uma visão e uma descrição fabulosa da realidade", substituindo-se, por conseguinte, "a vida real por uma utopia" (HAUSER, 1982 II, p. 829).

Muitos diriam que o motivo desta concepção reside no fato de a arte não possuir um fim prático; que ela não manteria com o ambiente à sua volta a menor correspondência, de vez que as representações artísticas o transporia - posto que em alguns casos ofereçam dele uma descrição mais direta, tal como se deu, por exemplo, com a abordagem naturalista, cientificamente orientada, do Quattrocento, ou com o realismo de um Courbet, na segunda metade do século XIX, em um desejo sincero de se mostrar o real na maneira como este se nos apresenta, isto é, no plano agudo de suas contradições. Mas, em verdade, não lhe cura de ser a vivência 
propriamente dita senão um "naco", um "fragmento", ou ainda, se se preferir, uma "ontologia regional".

De todo modo, a concepção de um lugar próprio às manifestações estéticas ganhará destaque. Ainda que fosse um instrumento teórico para o conhecimento sistemático e racional da realidade objetiva (da "natureza"), como aconteceu no século $\mathrm{XV}$, a arte, num sentido mais amplo e geral, parece localizar-se mesmo num tipo de

esfera isolada do resto do mundo, na qual é possível organizar uma vida intelectual e entregar-se a prazeres intelectuais de uma espécie inteiramente particular. Quando alguém se move neste mundo da arte, separa-se tanto do mundo transcendente da fé como do mundo das realidades práticas (ibid. I, p. 438).

O terreno artístico, em outras palavras, estaria situado à parte, destinado a um público e classe social específicos, quer dizer, servindo ao gosto e interesse dos grupos dominantes. Aliás, este é o conceito defendido por um estudioso contemporâneo, Kurz (1999), para quem a arte, nos dias de hoje, por conta de fatores econômicos e culturais, ver-se-ia desligada de todos os departamentos da vida social: aquela não compreenderia outra coisa senão "l'art pour l'art", ou a idéia, tal e qual a defendida na Renascença, "de que as formas culturais são independentes das leis externas" (HAUSER, 1982 I, p. 435). Com efeito, o novo predicativo que se lhe atribui constitui problema dos mais graves à sombra da autonomização capitalista. O surgimento de concepções "bizarras" e sobretudo "banais" reflete, pois, a fratura operada no seu ser próprio, naquilo que pode e deve articular: "uma reflexão estética da sociedade e da relação humana com o mundo" (KURZ, 1999). Na condição de fetiche, portanto, torna-se incapaz de fazer deitar sobre o real os elementos de uma ou outra ideologia (o que, do contrário, designaria algo vital, dado o dinamismo que representa ante as visões mais "fechadas" acerca do mundo e da vida).

Vistos assim, em todo o seu conjunto, os fatos estéticos 
devem ocupar lugar novo à conta da teoria que invoca os elementos centrais de sua produção, baseando-se no papel social que desempenham. Ora, num tal ponto de vista, a arte não se afastaria de sua função estética, quer dizer, do modo como atua sobre as faculdades do espírito e a sensibilidade do homem mediante suas formas de expressão; mas é que ela é também um "produto social", e que portanto o fazer artístico, ao invés de ser considerado isoladamente - como que nos recessos de uma "jaula de vidro" -, exprime as mais variadas demandas coletivas, antes e depois de sua realização. Assim, é igualmente tarefa do crítico não se distanciar das referências sociais e históricas que, de algum modo, todo universo estético encarnará.

Desde já, contudo, é indispensável localizar outro problema muito comum na arte em geral, assim como em todas as atividades que, geração após geração, assistem o homem de gênio no conhecimento reto do mundo. Não se tratando, como foi visto a pouco, de uma concepção idealista, mas da expressão de certa "mentalidade", entrando aí elementos do próprio sistema social, a representação estética parece encarar a vida com mais justeza: ela é, segundo esse enfoque, real. Em contrapartida, à imagem artística que, neste mundo e num só movimento, nada da experiência corrente venha cobrir, desfalcando a razão para o entendimento acerca das coisas, chamamos muito naturalmente de irreal.

É daí que procede todo juízo de valor com relação à obra de arte em suas formas de expressão. No terreno próprio da dualidade real-irreal, aquilo que o artista revela pode ser avaliado ou bem como fantasioso, absurdo, ou bem como objetivo, "verossímil". $\mathrm{Ou}$ a obra guarda proporções que se ajustam mais facilmente ao real (quer dizer, exibiria certo ar inteligível), ou, do contrário, escapa à convenção e seu material é reputado incoerente, fora dos padrões. Por isso que, no diálogo com a arte, não é possível considerar apenas seus iniciados e o movimento mais amplo da crítica, mas de igual modo o público leigo, pouco ou nada habituado às ferramentas da criação estética (técnicas, idéias, prescrições). Assim, alistada nos círculos da realidade ou do imponderável, a arte sofre 
de um julgamento que prolonga, antes e depois, certa dimensão ideológica; para aquela afluem valores que só podemos explicar em função de um contexto histórico determinado. Ora, o resultado de tudo isso é que situamos a obra dentro de condições próprias de lugar e tempo.

De início, quando lemos os contos d'As mile uma noites, somos tomados por um sentimento de estranheza em relação à série de imagens evocadas. É justamente aí que ocupará lugar central uma maneira toda própria à exteriorização de nossa "visão de mundo". É porque o fazer artístico atua como fator preponderante para desencadear sentimentos vivos: seu produto final agrada ou desagrada, podendo exercer sobre nós uma influência diretora importantíssima. A obra, no todo ou em parte, é sempre o modo de ser de um valor histórico - socialmente traduzível quando incorporado ao plano geral de uma estrutura de pensamento previamente fixada.

Nas histórias d'As mil e uma noites, podemos, aqui e ali, e de modo claro, apurar um sem-número de episódios que em nada obstam nossa compreensão do mundo. Tal recolta deve-se, fundamentalmente, à constância dos seus elementos temáticos: inveja, ciúme, vingança, cobiça, bravura, prudência, ou seja, uma série de noções que o leitor ocidental reconhecerá como sendo sua. Em alguns casos, como em dado momento da "História do cavalo encantado", o efeito de realidade atinge um nível de coerência tão profundo, "elementar", que chega a nos dar a impressão de que as circunstâncias nas quais se verifica constituem, em sentido próprio, cópia fiel do cotidiano, e com tanta mais expressão de concretude no comezinho das imagens. É o que mostra a passagem em que o príncipe Firuz desperta para seu primeiro dia, como hóspede ilustre, no palácio da princesa de Bengala:

O príncipe da Pérsia, que ganhara de dia o que perdera de noite, e que se recompusera perfeitamente da sua penosa viagem, acabava de se vestir quando recebeu os bons-dias da princesa de Bengala por uma das suas aias (As mil e uma noites, s/d, p. 61). 
Ou ainda o sortimento do grande mercado, que a "História do príncipe Amed e da fada Pari-Banu” nos descreve:

Depois de uma caminhada de cerca de quatro meses, chegou finalmente a Xiraz, que era então a capital do reino da Pérsia. Como estabelecera amizade e sociedade pelo caminho com um pequeno número de mercadores (...), hospedou-se com eles no mesmo khan.

No dia seguinte, enquanto os mercadores abriam os seus fardos de mercadorias, o príncipe Ali (...), depois de mudar de traje, fez-se conduzir ao bairro onde se vendiam as pedrarias, as obras de ouro e prata, os brocados, os tecidos de seda, os panos finos e as outras mercadorias mais raras e preciosas (ibid., p. 88).

Essas descrições têm destaque, sobremaneira, por conta do seu realismo demasiado simples. A tal ponto que podemos divisálas como sendo para nós as mais "próximas"; e mais exatamente isso, já que coloca diante do leitor do Ocidente, por extensão, um panorama da vida social na Idade Média. Falamos do exato instante em que o renascimento urbano aí se impõe; quer dizer, $\mathrm{da}$ ameaça que as comunas fortificadas experimentam em face do faubourg, que não respeita seus limites, mostrando toda a vitalidade do comércio itinerante, e que é condição básica para se estabelecer, com exceção na cronologia, um paralelo entre o Ocidente e o Oriente. Finalmente exibem, tal como o fizeram nossos romances de cavalaria, as intimidades da realeza, as quais povoaram o medievo europeu a partir das noções de luxo e volúpia, estendendo-se até nossos dias. De tal sorte que, para o Oriente, essas narrativas formam toda uma documentacáa: os contos d'As mile uma noites dissertam "sobre as ruas nas grandes cidades árabes, sobre os costumes dos mercadores, sobre a vida social, sobre a religião muçulmana" (ibid., p. 12, nota introdutória). E isso com um senso de objetivação admirável.

Essa nossa posição, contudo, é arbitrária. Porque o leitor, as 
mais das vezes, não atentará para associações dessa natureza. Em geral, por causa de uma postura etnocêntrica, refuta as idéias de outro tempo e lugar, como se estas não lhe dissessem respeito; vêse tomado comumente pela admiração, quando sua imaginação as sobrevoa baixo, e pelo arrebatamento, em razão de não encarar como fictícias as "evocações brilhantes", levando todas a sério. Com efeito, para o universo do leitor, afetado pelo excêntrico de algumas concepções - poligamia, haréns, eunucos -, as imagens d'As mil e uma noites acabaram por adquirir um sentido negativo dentro de um valor profundamente real, chegando a fazer "crer à Europa enganada que existia [no Oriente] uma região de felicidade sem limites" (ibid., p. 13, nota introdutória).

Mas é preciso perguntar, no que concerne à dicotomia realirreal, o que, na esfera essencial da produção do discurso, é e não é "fictício". Ou melhor: por que, em alguns casos, compreendemos a ficção pelo ângulo da realidade e, no caminho oposto, colocamos aquela no lugar desta? Ora, tudo isso dependerá de uma série de fatores; sobretudo se o discurso convence, a ponto de influir, enfaticamente, em nosso modo de ser.

Diz Luis Filipe Ribeiro (1999, p. 125-126) que o autor "consubstancia (...) visões de mundo que pertencem à sua sociedade e ao seu tempo". De forma idêntica, o leitor apóia-se em "parâmetros adquiridos na aprendizagem em sociedade" (ibid., p. 126): faz correr pela obra uma série de valores que tocam as condições gerais de determinado tempo e lugar; em relação à obra propriamente dita, estes se lhe incorporam ao núcleo mais íntimo através da concepção de mundo do autor, a qual se integra ou não ao sistema simbólico de onde parte. Daí a importância das histórias d'As mil e uma noites, do modo como foram, a pouco e pouco, socialmente estruturadas: representam elas, em verdade, o produto da colaboração de inúmeros artistas (iranianos, árabes, egípcios), manifestando os preceitos desta, dessa ou daquela formação social. Pois que, de agora em diante, tais narrativas constituem, por um lado, um documento vivo, já que agrupam a história de vários povos, e, por outro, a coroação de um estilo literário: o realismo 
fantástico.

Por conta deste último ponto, a oposição real-imaginário, mantendo intacto seu fundamento, nem tenderá à ficção nem a descrições áridas da vida humana e natural. De modo que se eleva até a esfera do discurso, cuja matéria é ao mesmo tempo realista e imaginosa, tendo em vista o ser precário da linguagem em face do que é dinâmico na cultura. Porque

quando a cultura muda, as concepções dominantes em uma dada cultura mudam igualmente. Surgem então necessariamente novos pontos de vista que servem para a apreensão, a apreciação e a coordenação dos dados (DEWEY, apud Schaff, 1995, p. 271).

Em Lalo (1964), por exemplo, a dimensão social desempenha, em toda a espessura da obra, papel fundamental - mesmo que se valha da explicação econômica para os fenômenos de estética (o que é bastante sugestivo, dado o mundo de mercadores d' $A s$ mil e uma noites). De qualquer forma, vincula a produção artística (“discursiva”) a grupos dirigentes da sociedade:

Foi um público burguês de comerciantes e de proprietários de terras que pediu aos pintores holandeses do século XVII seus retratos de família ou de corporações, suas cenas de gênero popular, suas marinhas ou suas paisagens sóbrias (...) Na literatura, esta influência das condições econômicas gerais é ainda mais nítida. Quando a agricultura está na ordem do dia e passa por uma espécie de renascimento, pelo menos nas altas classes, o gênero pastoral multiplica-se imediatamente (apud Cuvillier, 1964, IV, p. 1983).

Por fim, é chegado o momento de se decidir pelo lado fulgurante da moeda, em que a ficção designará também uma "forma de discurso". A seu abrigo, fazemos circular idéias cujas imagens (por causa do significado social que trazem) lançam-se a iluminar toda realidade humana. É nosso objetivo, portanto, 
mostrar de que maneira o "irreal" - o elemento fantástico d' $A s$ mil e uma noites -, liga-se, direta e principalmente, à ordem concreta do mundo.

No mais das vezes, somos arrastados por uma inclinação quase invencível de atribuir às obras de ficção um valor que é somente estético. Muitos olvidam o lado prático que de algum modo elas esclarecem, posto que de forma aberta. Mas talvez seja de pouco efeito uma tomada de posição ao contrário. Isso se explica, primeiro, em função de certo positivismo da crítica, preocupada só com o aspecto formal das obras, com bem pouco a dizer sobre os fatores que lhes norteiam a produção (a não ser que mostrem a influência direta da moda vigente, ou mesmo das desaparecidas, que refletiriam as solicitações de outro tempo social); em segundo lugar, devido ao preconceito de se lhes indicar a ideologia do artista, e por isso mesmo a deixando de fora nos estudos de arte. Seja como for, a experiência estética assinala, conforme foi visto em dada altura, o resultado concreto de determinações próprias, exprimindo certa concepção da realidade material por meio de uma "técnica socialmente organizada e consentida" (ibid., p. 1983).

Quanto a esse "lado prático", ninguém melhor do que Walter Benjamim (1994) para descrevê-lo em um de seus traços fundamentais. À noção de praticidade corresponderia, de maneira positiva, a pedra de toque da grande narrativa épica. Esta se situa, pois, no campo do "discurso vivo", em virtude de seu aspecto utilitário; em outras palavras, ela teria por função "dar conselhos". E essa prática do aconselhamento se traduz na qualidade de um "ensinamento moral", de um "provérbio", ou ainda de uma "norma de vida", até porque "o narrador é um homem que sabe dar conselhos" (ibid., p. 200).

Mas do que isso, conclui-se que a narrativa não refletirá, mesmo no seio do elemento fantástico, o costume freqüente de explicar aquilo que se conta. Ora, "metade da arte narrativa está em evitar explicações” (ibid., p. 203). Todas essas aventuras, repletas de feitos portentosos de compleição lendária única e abrangente; ou ainda que seja a história primordial da comunidade aldeã, montada 
sobre o vínculo estreito entre o dado efêmero e a plenitude do mito, conferem a seus leitores e ouvintes grande liberdade de interpretação. De tal modo que atingem uma amplitude notável, fundamental para a manutenção secular da narrativa.

Os contos d'As mile uma noites nos dão uma demonstração clara de como o senso prático é capaz de sublinhar, no curso dos fatos, algumas noções de fundo moral, e que esclarecem, tanto quanto possível, os meandros da vida de relação.

Tomemos, como exemplo, a "História de Ali Cogia, negociante de Bagdá”. Em um sonho (na verdade são três), um "velho venerável, de olhar severo", censura Ali pelo fato deste nunca ter peregrinado a Meca - o que, evidentemente, o leva a se decidir pela viagem. Como primeira medida, resolve por vender todos os seus pertences, salvo algumas mercadorias que, na cidade santa, podem ser negociadas a varejo. Uma vez tudo pronto, ocupase de pôr em acerto um último detalhe: guardar em segurança a quantia de mil moedas de ouro. Resolve o problema depositandoas no fundo de um pote, que preenche com azeitonas. Antes de partir, deixa-o sob os cuidados de um "negociante seu amigo" até o dia da volta. Este, é claro, desconhece o conteúdo valiosíssimo que tem em mãos.

Daí a tempos - sete anos depois -, Ali Cogia regressa (porque, de Meca, segue curso livre, sempre motivado por mercadores, que lhe anunciam as chances de lucro fácil com a venda de alguns itens; e tudo isso mediante essa estrutura econômica simples, baseada apenas na compra e venda de mercadorias). Para sua maior surpresa, o pote lhe é restituído sem as moedas - o que leva a coisa toda para o campo da dúvida, depois da desconfiança, da desavença, e, por último, da lei.

Na presença do cádi - espécie de juiz de Direito -, ambos os negociantes se revezam com os argumentos de acusação e defesa. $\mathrm{O}$ cádi, sem aprofundar os detalhes, dá por encerrada a controvérsia: o negociante desonesto, jurando inocência, é absolvido; isso deixa Ali furioso.

A saída é levar o caso, sob a forma de petição, ao conhecimento 
do califa Harun-al-Raschid, que a lê, marcando dia e hora da audiência.

À semelhança daquilo que Todorov (1970) chamaria "movimento entre dois equilíbrios", a história como que dá uma espécie de guinada.

Assim, o califa, como de costume, corre pela cidade à noite, sob disfarce, acompanhado do grão-vizir e do chefe dos eunucos. Em dado momento, ouve um grande número de vozes, e, dirigindose até elas, presencia um grupo de meninos, que encena um julgamento. Na verdade, trata-se de uma representação lúdica mas lúcida da audiência conduzida pelo cádi. Isso mostra que a história, sem mais, já pertence ao domínio público.

$\mathrm{Na}$ espreita, observa tudo com muita atenção, tomando ciência de que, no pote de Ali Cogia, recuperado após sete anos, os frutos ainda se acham em perfeito estado. O que prova um absurdo, já que "não valem nada ao fim do terceiro ano", mostrando que, desta forma, o lacre sofreu violação.

Poderíamos mesmo, com efeito, sugerir uma "sentença moral”; ou quem sabe extrair dessas histórias, de cada situação descrita, um pouco daquilo que corre a eito em cada um de nós; aquilo que pode habitar, sem qualquer reserva, o âmago do nosso ser: medo e cupidez, ódio e ressentimento. Todas essas forças diretoras são, antes do mais, "concretas", sendo que muitas vezes as plasmamos em ações depreendidas no curso geral do devir.

A história, em sua forma mais sensível, aponta para alguns valores ou elementos de objetivação: a fé operante de Ali Cogia ("bom muçulmano"); o cinismo do mercador desonesto, encontrando a morte na forca; a displicência no senso burocrático do cádi, que vai no contrário das suas atribuições; e, por fim, a inteligência e sensatez de um dos meninos atores (aquele que, fingindo ser o cádi, leva até seu termo a audiência de faz de conta).

Daí se concluir que essa história nada traz de fantástico e que por isso mesmo nos é mais “familiar". Até porque, diante de lunetas e tapetes mágicos, cavalos voadores, reinos subterrâneos, monstros 
e gênios, o leitor é capaz de não fazer a ligação necessária entre o que toma à sua volta como habitual e as imagens fantasiosas que o "desorientam". Vistos por este ângulo, todos esses contos não passariam senão de certa coisa pueril. Mas o que se dá de fato é algo bem diferente, uma vez que

o confronto com as dimensões históricas de outras sociedades e de outros tempos servirá para esclarecer e definir, ainda mais, [nossa] inserção na trajetória [da] sociedade, em primeiro lugar, e da humanidade como um todo, em última instância (RIBEIRO, 1999, p. 128).

Isso significa dizer que, sob esse aspecto, as imagens d' As mile uma noites figuram, igualmente, como o produto de uma realidade social e histórica considerada em todo o seu conjunto: já não importa o texto (um dado gráfico), mas as "relações discursivas" que elas firmam entre o passado e o presente. Em sentido profundo, efetuam um diálogo todo próprio entre quem lê (dentro de uma noção) e quem é lido (o autor, considerando os fatores sociais que influíram direta e indiretamente sobre seu modo de ser, bem como a grande chama de liberdade a qual lhe certifica originalidade, argumentação crítica e sutileza, e o que refuta, de todo, a tese idealista).

Isso nos dá a ver que, mesmo no interior do elemento fantástico, os contos d'As mil e uma noites se apresentam, de pleno direito, como "discurso vivo". Isso nos dá a ver, por tudo o que envolve, que seu enunciado pode ser entendido como a "expressão material de uma passagem", já que "por ele trafegarão as versões 
de mundo, as indagações, as perplexidades dos atores" (ibid., p. 139). Por conseguinte, surge como um "campo onde os valores se organizam para dar inteligibilidade ao mundo" (ibid., p. 139).

Assim sendo, cai por terra, efetivamente, a dualidade realimaginário. Como mesmo diz Todorov (1970, p. 165), “o objeto literário é ao mesmo tempo real e irreal; por isso, contesta o próprio conceito de real”. E porque expressa justamente uma realidade em devir, é que pode se mostrar cada vez mais rico no seio de suas imagens, povoando a mente dos homens, descrevendo o mundo como aquilo que efetivamente é: um todo complexo e contraditório, reflexo do que é concreto na experiência enriquecedora da humanidade.

\section{REFERÊNCIAS}

AUTOR DESCONHECIDO. As mil e uma noites. Tradução: Maria Eugênia de C. de Sá. Lisboa: Publicações Europa-América, s/d., v. 6.

BENJAMIN, Walter. O narrador. Considerações sobre a obra de Nikolai Leskov. In: . Magia e técnica, arte e religião. Ensaios sobre literatura e história da cultura. Obras escolhidas. Tradução: Sérgio Paulo Rouanet. 7. ed. São Paulo: Brasiliense, v. 1, 1994, p. 197-221.

CUVILLIER, Armand. Estética. In: Enciclopédia Delta Larousse. Tradução: Alberto Castiel. 2. ed. Rio de janeiro: Editora Delta, v. 4, 1964, p. 1982-1984. 
